\title{
Transgenic mice overexpressing human TNF-a experience early onset spontaneous intervertebral disc herniation in the absence of overt degeneration
}

\author{
Deborah J. Gorth', Irving M. Shapiro ${ }^{1}$ and Makarand V. Risbud (10 ${ }^{1}$
}

\begin{abstract}
There is a well-established link between cytokine expression and the progression of intervertebral disc degeneration. Among these cytokines, interleukin-1 $\beta$ (IL-1 $\beta$ ) and tumor necrosis factor-a (TNF- $\alpha$ ) are the most commonly studied. To investigate whether systemic hTNF-a overexpression affects intervertebral disc health, we studied the spine phenotype of Tg197 mice, a widely used hTNF-a transgenic line. These mice were studied at 12-16 weeks of age using comprehensive histochemical and immunohistological analysis of the spinal motion segment. Micro-CT analysis was performed to quantify vertebral trabecular bone architecture. The Tg197 mice evidenced spontaneous annular tears and herniation with increased vascularity in subchondral bone and significant immune cell infiltration. The fullthickness annular tear without nucleus pulposus (NP) extrusion resulted in neutrophil, macrophage, and mast cell infiltration into the disc, whereas the disc with full-thickness tear and pronounced NP herniation showed additional presence of CD4+ and CD8+ T cells. While the observed defects involved failure of the annular, endplate, and vertebral junction, there were no obvious alterations in the collagen or aggrecan content in the NP and annulus fibrosus or the maturity of collagen fibers in Tg197 mice. Despite elevated systemic inflammation and pronounced loss of trabecular bone in the vertebrae, intact Tg197 discs were healthy and showed an increase in NP cell number. The NP cells in intact discs preserved expression of phenotypic markers: CAlll, Glut1, and Krt19. In conclusion, elevated systemic TNF-a increases the susceptibility of mice to spontaneous disc herniation and possibly radiculopathy, without adversely affecting intact intervertebral disc health.
\end{abstract}

\section{Introduction}

Low back pain (LBP) is a profoundly debilitating and increasingly prevalent condition with a huge societal $\operatorname{cost}^{1}$. LBP is currently the leading cause of disability worldwide; a recent study of the US and global population ranked LBP as the first, and neck pain as the fourth condition for years lived with disability ${ }^{2,3}$. The health of the intervertebral disc is intricately linked with $\mathrm{LBP}^{4}$.

Correspondence: Makarand V. Risbud (makarand.risbud@jefferson.edu) 'Department of Orthopaedic Surgery and Graduate Program in Cell Biology and Regenerative Medicine, Thomas Jefferson University, Philadelphia, PA, USA Edited by M. Kaartinen
Patients with severely degenerated discs are 3.2 times more likely to suffer from $\mathrm{LBP}^{5}$.

The disc comprises an inner gelatinous glycosaminoglycan-rich nucleus pulposus (NP) surrounded circumferentially by an organized fibrocartilaginous annulus fibrosus (AF) and inferiorly and superiorly by cartilaginous endplates (CEP). Disc degeneration is characterized by increased fibrosis and decreased proteoglycan content in the NP leading to reduced ability of the tissue to bind and retain water, thereby compromising the mechanical properties of the motion segment ${ }^{6-8}$. There is also evidence of increased cell death and a transition from notochordal cells to cells that exhibit the

\section{(c) The Author(s) 2018}

(c) Open Access This article is licensed under a Creative Commons Attribution 4.0 International License, which permits use, sharing, adaptation, distribution and reproduction c. in any medium or format, as long as you give appropriate credit to the original author(s) and the source, provide a link to the Creative Commons license, and indicate if changes were made. The images or other third party material in this article are included in the article's Creative Commons license, unless indicated otherwise in a credit line to the material. If material is not included in the article's Creative Commons license and your intended use is not permitted by statutory regulation or exceeds the permitted use, you will need to obtain permission directly from the copyright holder. To view a copy of this license, visit http://creativecommons.org/licenses/by/4.0/. 
characteristics of hypertrophic chondrocytes ${ }^{7,9}$. Proinflammatory cytokine expression is correlated with the severity of disc degeneration ${ }^{10}$. Several studies have shown that degenerated discs exhibit increased expression of chemokines and inflammatory cytokines, and there is evidence of immune cell infiltration ${ }^{11,12}$. Inflammatory cytokines are produced both by NP and AF cells as well as by infiltrating immune cells in herniated discs. Through activation of matrix metalloproteinases (MMPs) and other proteases, cytokines cause extracellular matrix breakdown and enhance recruitment of immune cells thereby perpetuating and promoting the inflammatory environment $^{13-15}$. Among these cytokines, interleukin-1 $\beta$ (IL-1 $\beta$ ) and tumor necrosis factor- $\alpha$ (TNF- $\alpha$ ) are the most commonly studied. In addition to its primary physiological role, the regulation of immune cell function, TNF- $\alpha$ paradoxically induces both apoptotic cell death as well as cell proliferation and differentiation ${ }^{16-18}$. TNF- $\alpha$ dysfunction has been implicated in the pathogenesis of numerous disorders, including rheumatoid arthritis, asthma, septic shock, irritable bowel syndrome, and most relevant to the present study, intervertebral disc disease $^{19,20}$. Anti-TNF- $\alpha$ therapies are currently being investigated for the treatment of disc degeneration, albeit with mixed results ${ }^{21-23}$.

TNF- $\alpha$ is elevated in numerous systemic inflammatory conditions related to disc health. High levels of circulating cytokines including TNF- $\alpha$ are seen in patients suffering radiculopathy following disc herniation ${ }^{24,25}$. Olmarker and colleagues have shown that TNF- $\alpha$ recapitulates effects of herniated NP tissue on dorsal root ganglion apoptosis in a rat model of disc herniation ${ }^{26}$. Similarly, a recent study by Lai et al. has demonstrated increased pain behavior when TNF- $\alpha$ was injected in a rat model of disc puncture $^{27}$. Additionally, elevated levels of TNF- $\alpha$ in individuals with high body mass index correlates with both disc degeneration and $\mathrm{LBP}^{28}$. Increased TNF- $\alpha$ is also seen in diabetic patients, a systemic inflammatory condition correlated to disc disease ${ }^{29,30}$. Likewise, inflammation in the neighboring vertebrae is associated with symptomatic disc disease. Modic Type 1 changes are strongly correlated with LBP and are indicative of bone edema linked to inflammation ${ }^{31,32}$. Importantly, there is a link between marrow edema and levels of circulating TNF- $\alpha^{33}$. In summary, despite the association between inflammation and disc disease, particularly elevated TNF$\alpha$ levels, the causative relationship between this cytokine and disc disease is not firmly established.

A human TNF- $\alpha$-overexpressing transgenic mouse line (Tg197) is widely used to investigate the role of systemic hTNF- $\alpha$ overexpression in inflammation-driven pathologies $^{34-36}$. These mice exhibit early-onset polyarthritis that affects major arthrodial joints; this is characterized by robust inflammation and structural degradation of synovium, articular cartilage, and bone. To examine the contribution of elevated systemic TNF- $\alpha$ levels and vertebral bone inflammation to disc herniation and degeneration, we characterized the spinal phenotype of $\operatorname{Tg} 197$ mice. Our studies show that chronic inflammation due to elevated systemic TNF- $\alpha$ promotes annular tears, herniation, and consequently immune cell infiltration in the discs. Surprisingly, unaffected discs maintained their structural integrity with minimal changes in the NP and AF tissues.

\section{Results}

Tg197 mice show a higher incidence of disc herniations characterized by immune cell infiltration

Our analysis of Tg197 mice at 12-16 weeks showed that three of the ten animals exhibited spontaneous disc herniation at one of the three caudal levels interrogated (Fig. 1a, b). In contrast, none of the discs in wild-type (WT) mice showed signs of annular defects or herniation. In one instance, the annular tear appeared as a cleft across the entire width of the AF, stretching from the endplate-AF junction to the NP (Fig. 1a). There was a large population of cells that infiltrated into the aggrecan matrix of the NP; the remnant NP cells did not display the vacuolar morphology of healthy discs (Fig. 1a, a'). The other herniated disc also exhibited a full thickness cleft; however, the NP extracellular matrix and cells had extruded outside the disc space and were surrounded by cells (Fig. 1b). The cell response at the site of herniation disrupted the integrity of the growth plate adjacent to the endplate-AF junction. To verify the identity of the infiltrating cells and to further characterize the nature of the response, we performed immunofluorescence staining using a panel of well-defined immune cell markers.

In the NP compartment of discs exhibiting annular tear only, cells stained positive for CD68: a macrophage marker, Ly6: a neutrophil marker, and Tryptase: a mast cell marker (Fig. 1c-e'). However, staining for both CD4 and CD8, $T$ cell markers, was limited and confined to few positive cells in the vasculature of the neighboring vertebral body (Fig. 1f, g'). Tryptase-positive cells were most often centrally located in the NP (Fig. 1e, e'), followed by CD68-positive cells (Fig. 1c, c'); the Ly6-positive cells were clustered between the CD68+ cells and the endplate-AF end of the cleft (Fig. 1d, d'). The lack of T cell staining in the disc with annular tears suggested this to be an acute event (Fig. 1f, g'). In contrast, in addition to other immune cell types (Fig. $1 \mathrm{~h}-\mathrm{j}$ ), the disc with both AF tear and NP extrusion stained positive for CD4 and CD8 (Fig. 1k, l'). The staining for all the cell types was most pronounced in the vertebral body adjacent to the endplate-AF junction through which the AF cleft propagated and did not show any specific pattern. To gain an overall understanding of the nature of this immune response, the staining for each 


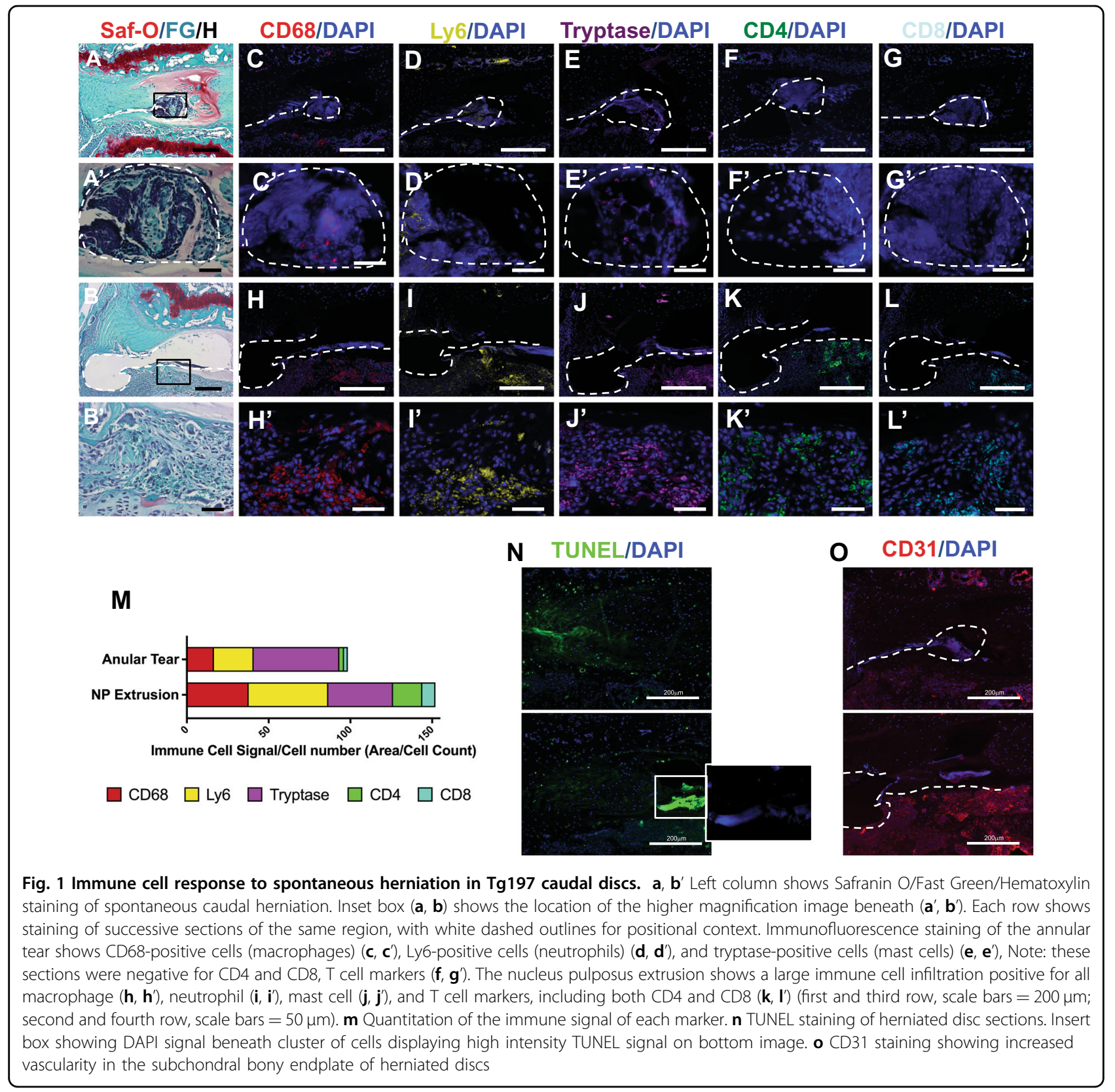

marker was quantified (Fig. 1m). It is interesting to note that herniation lead to extensive cell death in the disc compartment (Fig. 1n). In addition, both types of herniated discs showed elevated CD31 staining in the subchondral bony plate, suggesting increased vascularity (Fig. 1o).

\section{Tg197 mice do not show evidence of early-onset disc degeneration in intact discs}

Tg197 mice have been characterized for their arthritic phenotype. The transgenic animals are smaller than their age-matched WT controls and display signs of arthritic limb malformation and impaired movement ${ }^{34,36}$. Safranin $\mathrm{O} /$ Fast green and hematoxylin staining showed that the overall tissue structure of intact caudal and lumbar discs was well preserved and comparable to WT control animals (Fig. 2a-h'). The discs of Tg197 mice were healthy, as evident by the abundant aggrecan-rich extracellular matrix in the NP compartment, vacuolated notochordal $\mathrm{NP}$ cells, and well-organized lamellar collagen-rich AF (Fig. 2a-h'). Interestingly, the NP tissue of intact Tg197 discs was more cellular, and the cells appeared larger and 


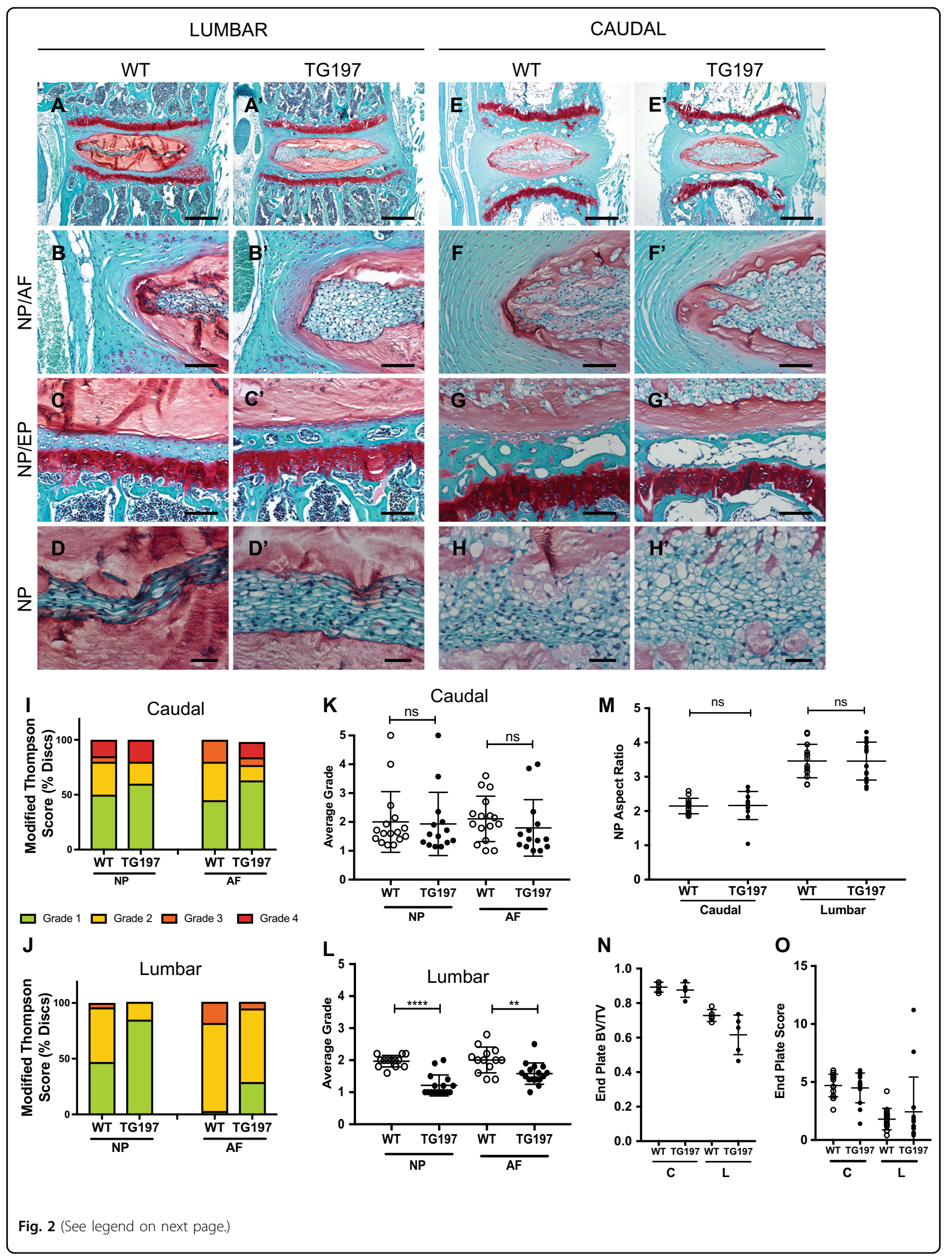


(see figure on previous page)

Fig. 2 Tg197 discs are healthier or no different than wild-type controls. a-h Safranin O/Fast Green/Hematoxylin staining of coronal sections of wild-type and Tg197 mouse intervertebral discs. Low magnification images of lumbar Tg197 discs show thickening of the nucleus pulposus cell band. (top row, scale bars $=200 \mu \mathrm{m}$; middle rows, scale bars $=50 \mu \mathrm{m}$; bottom row, scale bars $=20 \mu \mathrm{m}$ ) $\mathbf{i}$, $\mathbf{j}$ Distribution of histological grades using the modified Thomson scale for $\mathbf{i}$ caudal and $\mathbf{j}$ lumbar intervertebral discs. $\mathbf{k}$, I Average modified Thompson score for $\mathbf{k}$ caudal and I lumbar intervertebral discs. $\mathbf{m}$ Aspect ratio of caudal and lumbar nucleus pulposus. $\mathbf{n}$ Bone volume/total volume of endplate in Tg197 and control mice ( $n=5$ mice/ genotype). o Endplate scoring of caudal and lumbar discs. Data was collected from 3 discs per mouse ( $n=10$ mice/genotype). Significance between average grades was determined using unpaired $t$ test. ns $=$ not significant, ${ }^{* *} p \leq 0.01,{ }^{* * *} p \leq 0.0001$

vacuolated than the WT controls (Fig. 2a-h'). Unlike the cartilages in other affected joints, the endplates in Tg197 mice showed normal morphology with a layer of hyaline cartilage (CEP) and a subchondral bone plate that was comparable to WT controls (Fig. 2c, c', g, g').

To quantitatively assess the histological changes, we used modified Thompson grading and Boos scoring as described previously ${ }^{7,37}$. No apparent differences in the distribution of NP and AF grades were seen for either the lumbar or caudal discs (Fig. 2i, j). To gain further insight into disc health, we compared average NP and AF grades. There was no significant difference between the average grade of caudal NP or AF (Fig. 2k). Interestingly, the average lumbar NP and AF grade in Tg197 mice was significantly lower than the WT control animals (Fig. 2l). Additionally, there was no difference in the NP aspect ratio between the two genotypes (Fig. $2 \mathrm{~m}$ ). Furthermore, micro-computed tomography $(\mu \mathrm{CT})$ analysis of the bony endplate showed comparable bone volume per total volume (Fig. 2n), and Boos scoring showed no differences in endplate scores between the genotypes (Fig. 2o). Together, these results suggested that the lumbar discs of hTNF- $\alpha$-overexpressing mice were healthier than the WT controls. Western blot analysis was performed using a specific hTNF- $\alpha$ reactive antibody confirming that hTNF$\alpha$ was present in the disc of Tg197 mice (Fig. S2A-C). Additionally, immunofluorescence staining of Syndecan 4, a downstream target of TNF- $\alpha$ in the disc, showed increased expression further indicating that there was elevated TNF- $\alpha$ activity in the Tg197 discs (Fig S2D) ${ }^{38,39}$. Together, these results suggested that the Tg197 mice do not evidence signs of early-onset disc degeneration in intact spinal levels.

\section{The expression of major disc matrix components is unaffected in $\mathrm{Tg} 197$ mice}

To assess whether the difference in herniation incidence was due to alterations in the AF matrix composition, we investigated the expression and localization of specific collagens using immunofluorescence staining. Surprisingly, there were no differences in expression levels and localization of collagen I and II between WT and Tg197 discs (Fig. 3a). However, there was a slight increase in collagen X staining in the Tg197 NP compared to WT controls (Fig. 3a). To gain further understanding of the overall collagen architecture and compositional makeup of these discs, Picrosirius Red staining was performed and the collagen birefringence, as an indicator of fiber diameter and maturity, was observed under polarized light ${ }^{40}$. As expected, AF showed strong birefringence, while NP tissue lacked any signal. Quantitative analysis showed that the distribution of fiber sizes in AF was nearly identical between the two genotypes (Fig. 3c). It is important to note that while collagen II is the primary collagen in the $\mathrm{NP}$ its concentration in the mouse disc is extremely low compared to that of the AF (Fig. 3b). This is supported by both the immunofluorescence and polarized microscopy, along with previously published studies (Fig. 3a, b) ${ }^{7,41}$.

To gain further insights into matrix composition and inflammatory environment of the Tg197 discs, we stained sections for chondroitin sulfate (CS), aggrecan core protein (Acan), IL-6, IL-1 $\beta, \quad$ MMP13, aggrecanase (ADAMTS-1, -4, and -5)-generated aggrecan N-terminal G1 neoepitope ARG (ARGxx), and MMP-generated Nterminal neoepitope sequence (DIPEN) (Fig. 4a, b). CS, MMP13, Acan, ARGxx, and DIPEN staining showed similar distribution in the NP and AF of WT and Tg197 animals (Fig. 4a, b). While IL-6 staining appeared pronounced within the vasculature of the subchondral bony endplate, quantification showed no significant difference between the genotypes (Fig. 4c). However, both IL-1 $\beta$ and IL-6 staining was significantly higher in Tg197 mice than in WT controls (Fig. $4 \mathrm{a}-\mathrm{c}$ ). Together, these results indicated that, while there were no gross compositional differences between the Tg197 and WT controls, there was some evidence of an altered inflammatory environment in the Tg197 discs.

Tg197 mice show increased cellularity in NP compartment

Safranin O/Fast green staining clearly showed increase cell number in the NP compartment of Tg197 mice (Fig. 1a). Consequently, we quantified the cellularity of the discs by counting the number of nuclei. The number of NP cells was significantly higher in Tg197 compared to WT animals (Fig. 5a). Not only were there more cells in the lumbar discs of Tg197 mice, but the NP cell band was more than twice as thick as the WT mice, suggesting a possible increase in size of the individual cells (Fig. 5b). To 

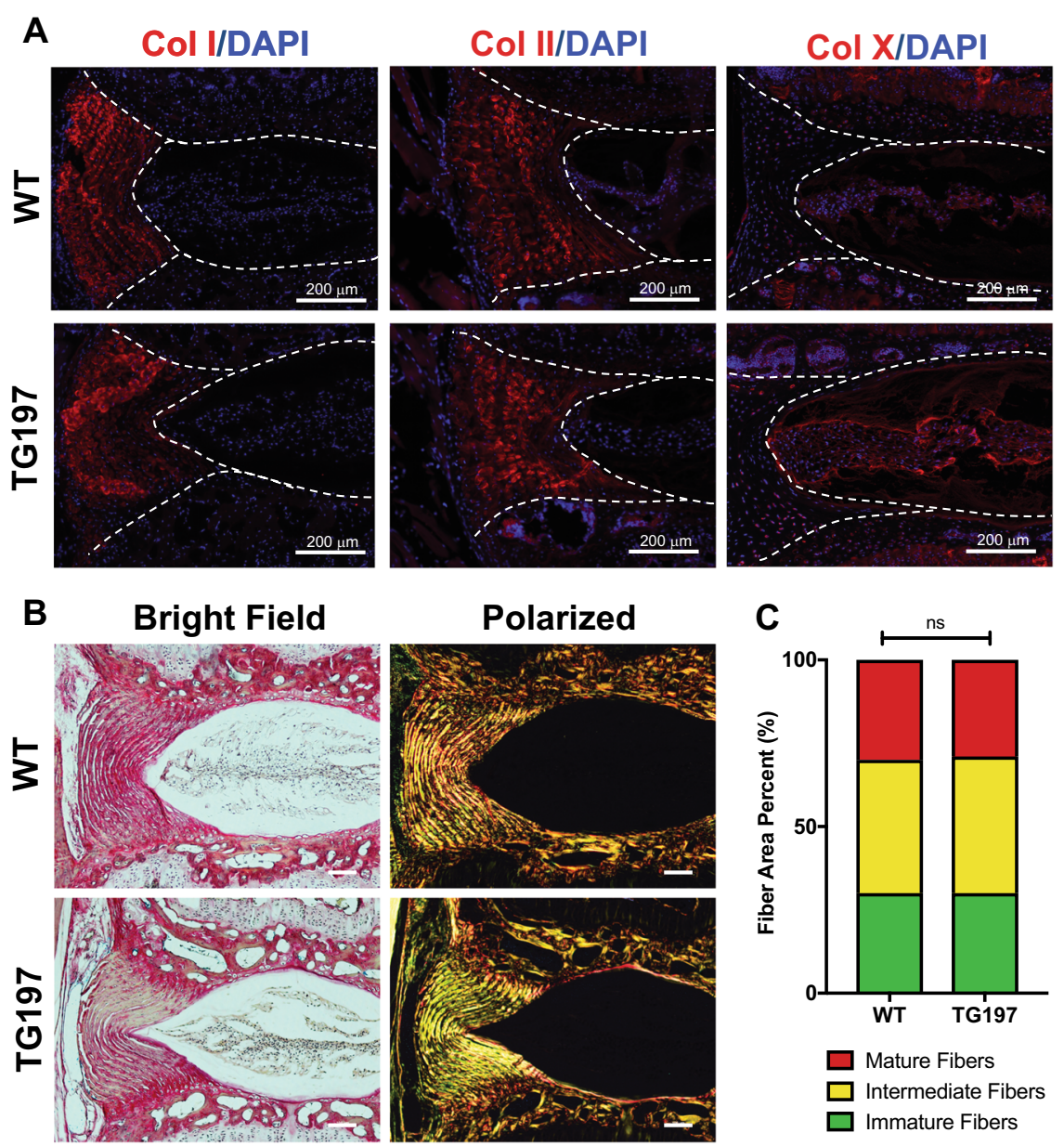

Fig. 3 Similarities in histology and immunohistochemistry of Tg197 and wild-type intervertebral discs. a Immunofluorescence staining of collagen I, collagen II, and collagen X (red). Collagen I and II showed similar distributions in the annulus fibrosus, while collagen X staining was confined to the nucleus pulposus and slightly elevated in the Tg197 disc. Dotted lines were drawn to distinguish different intervertebral disc compartments. All staining was performed using at least three animals per group. b Picrosirius Red staining of 16-week caudal discs showing collagen deposition in the annulus fibrosus and the nucleus pulposus. Collagen fibers visualized under polarized light (right column) show organized lamellae in (scale bar $100 \mu \mathrm{m})$. c Quantification of the fiber content distribution $(n=5)$. Significance between fiber distribution determined using $x^{2}$ test. ns $=$ not significant

determine whether the NP cells in Tg197 mice are phenotypically similar to WT animals, we measured the expression of known NP cell markers: carbonic anhydrase III (CAIII), keratin 19 (Krt19), and glucose transporter 1 $(\text { Glut } 1)^{42,43}$. There were no differences in expression and pattern of staining of any of the markers between the WT and Tg197 mice (Fig. 5c). To explore whether the change in cell number was due to active proliferation or cell death, CDK4 and terminal deoxinucleotidyl transferasemediated dUTP-fluorescein nick end labeling (TUNEL) staining was performed. At this age, there were no CDK4positive cells in either the Tg197 or control mice indicating a lack of cell proliferation. Additionally, there were few, if any, TUNEL-positive cells in both Tg197 and control mice (Fig. 5d). These results implied that the increased cell number in Tg197 did not arise owing to active cell proliferation or cell death at 12-16 weeks. In summary, these studies showed that disc of Tg197 mice have increased NP cellularity than their age matched WT controls, and these cells maintained their NP phenotype.

\section{Vertebral bone of Tg197 mice show characteristic thinning}

We performed $\mu \mathrm{CT}$ analysis to study vertebral bone properties and measure disc height. $\mu \mathrm{CT}$ studies revealed severe erosion in the lumbar and tail vertebrae (Fig. 6a). There was significant reduction in bone volume per total volume (BV/TV) in the caudal and lumbar vertebrae of Tg197 mice indicating bone erosion (Fig. 6b). Trabecular number (Tb.n.) was also significantly lower in Tg197 lumbar vertebrae (Fig. 6c). There was a significant reduction in trabecular thickness (Tb.th) in both caudal and lumbar levels (Fig. 6d), while trabecular spacing (Tb. 

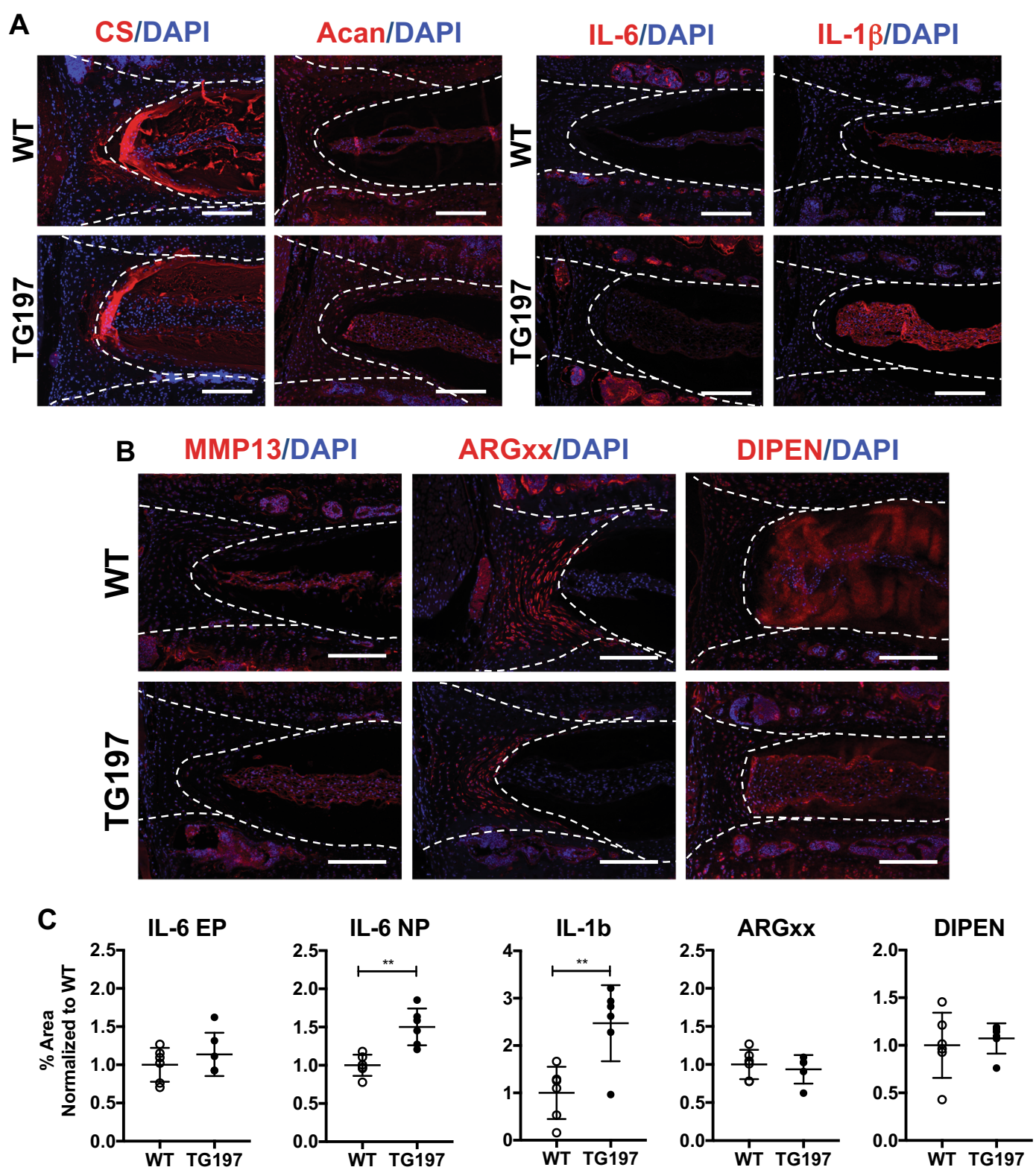

Fig. 4 Tg197 discs show altered inflammatory environment without changes in matrix composition. a Chondroitin sulfate (CS) and aggrecan (Acan) staining show no differences between WT and Tg197 ( $n=3$ animals/genotype), but IL-6 and IL-1 $\beta$ levels are increased in Tg197 NP ( $n=6$ animals/genotype). b MMP-13, ARGxx, and DIPEN show no differences in between the two genotypes. c Quantification of staining for IL-6, IL-1 $\beta$, ARGXX, and DIPEN performed using $n=6$ mice/genotype. ${ }^{* *} p \leq 0.01$ Dotted lines in $\mathbf{a}$, $\mathbf{b}$ were drawn to distinguish different intervertebral disc compartments. Scale bar $=200 \mu \mathrm{m}$

sp.) remained unchanged (Fig. 6e). There was a small but significant reduction in vertebral body length in the lumbar but not in the caudal spine of Tg197 mice (Fig. 6f), which was expected owing to the smaller size of the transgenic mice ${ }^{36}$. However, disc height and disc height index (DHI) showed no differences between the WT mice and Tg197 mice (Fig. 6g, h). These results indicated that the systemic inflammation in Tg197 mice severely affected the vertebrae without affecting disc height.

\section{Discussion}

Inflammation, intervertebral disc disease, and LBP are linked. It has been demonstrated that elevated tissue and systemic levels of inflammatory cytokines, in particular TNF- $\alpha$, characterize symptomatic disc disease ${ }^{12,25}$. However, despite many decades of research, the definitive cause and effect relationship between systemic inflammation and disc degeneration and herniation have not been adequately established in vivo. To explore the role of 


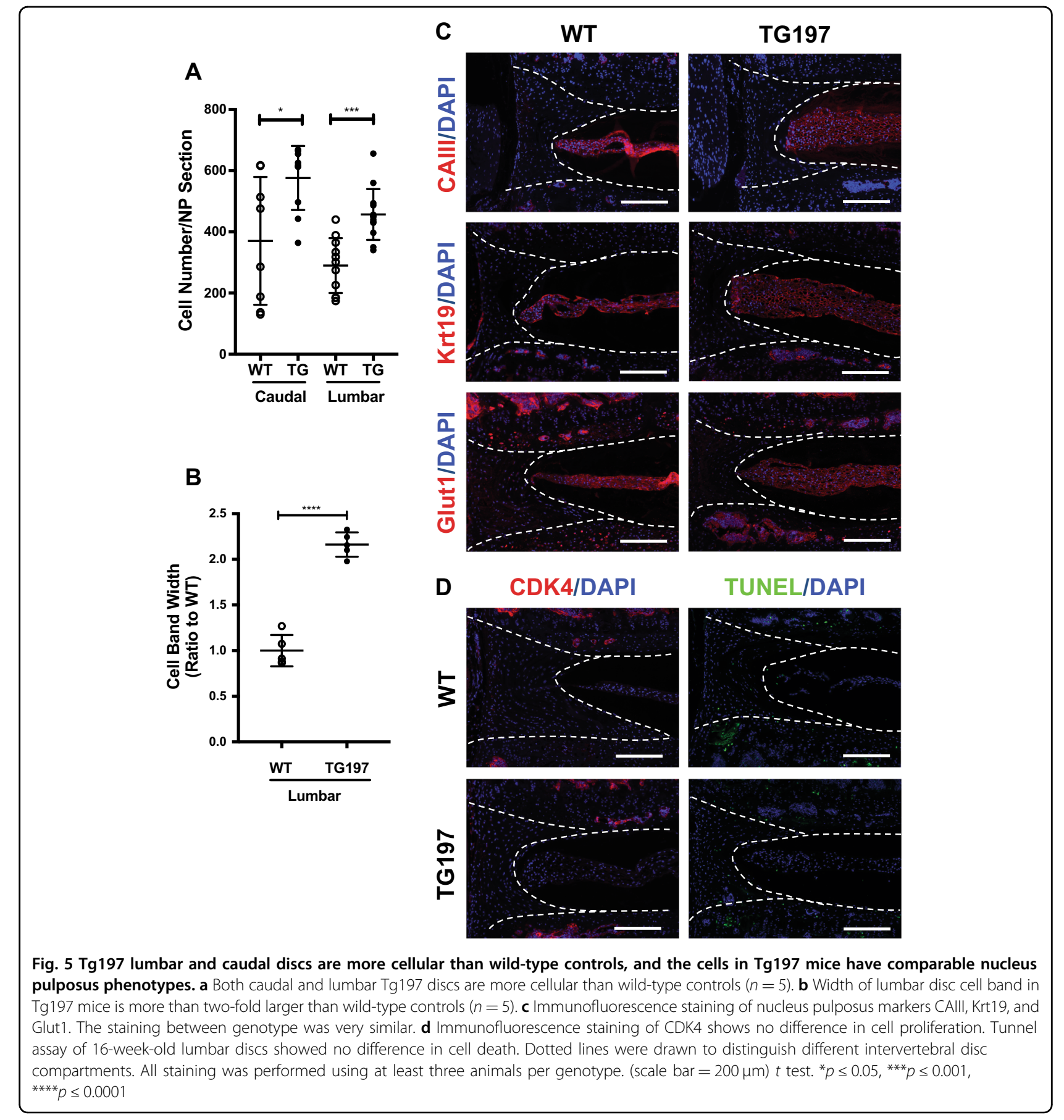

TNF- $\alpha$ and systemic inflammation in the pathogenesis of intervertebral disc disease, we used the Tg197 mouse, a well-established model of TNF- $\alpha$-driven systemic inflammation $^{34}$. We report here, for the first time, an indepth characterization of spinal phenotype in these mutant animals. Tg197 mice develop robust bone and joint inflammation. There was also increased incidence of spontaneous disc herniation in Tg197 mice that involved failure of the $\mathrm{AF}$, the $\mathrm{CEP}$, and tissue at the subchondral bone junction together with a robust immune cell response that was completely lacking in the WT animals. This type of failure is in accord with the clinical picture of disc herniation and the development of acute radicular pain $^{44}$. Surprisingly, despite the occurrence of spontaneous disc herniation, when intact, the Tg197 discs were healthier and evidenced increased NP cellularity compared to their WT controls. Based on these observations, we conclude that elevated systemic TNF- $\alpha$ predisposes 
animals to spontaneous herniation but is not sufficient to adversely affect the health of the intact discs at this timescale.

Spontaneous annular tears and NP herniation was a notable feature of the spinal phenotype of Tg197 mice, which have not been reported in mice at this early age $^{45,46}$. Gaining insight into the immune response to herniation has important clinical implications; many lumbar disc herniations regress spontaneously not necessitating costly surgery ${ }^{47}$. Current models of AF
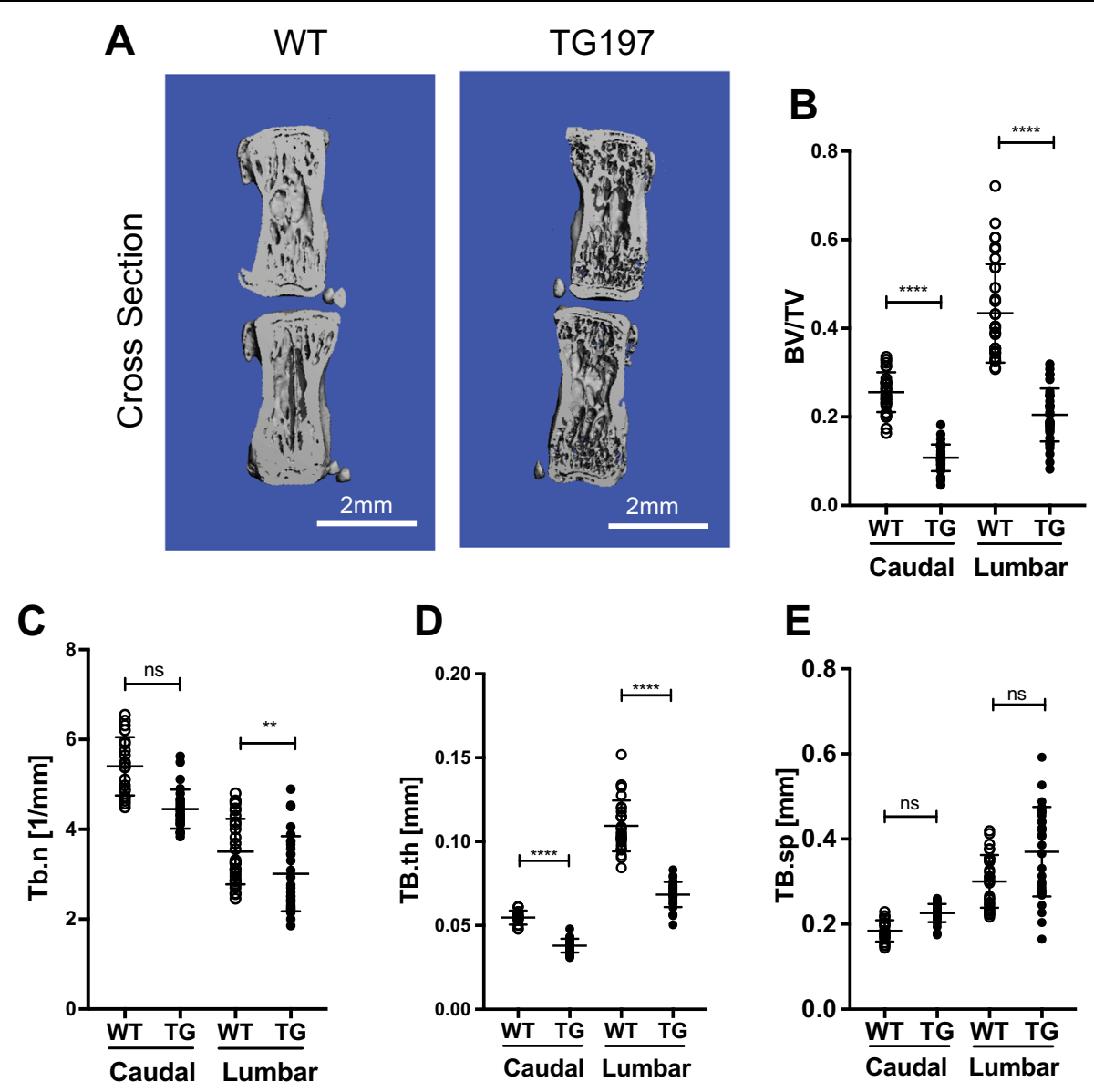

E
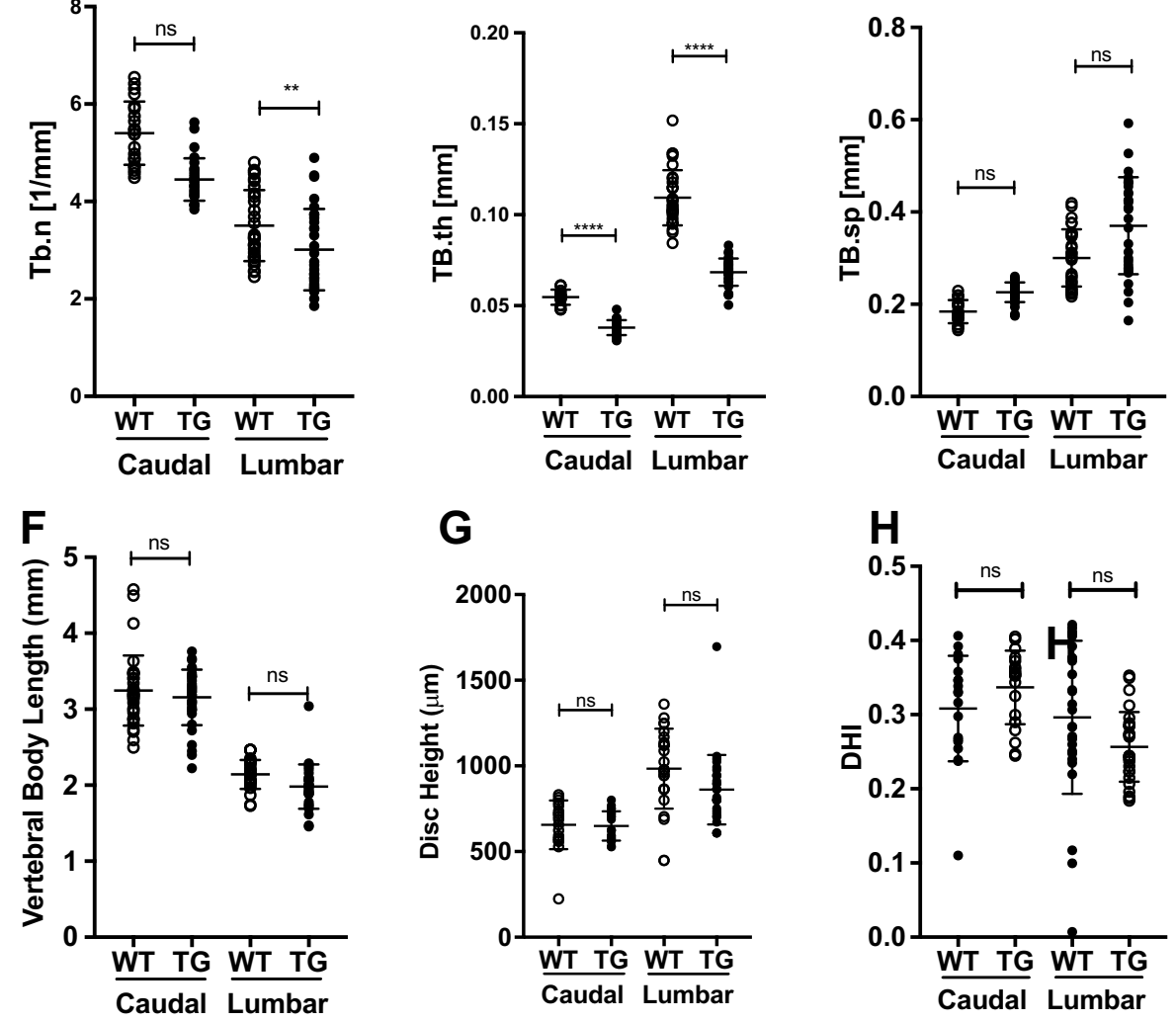

Fig. 6 Tg197 vertebrae show characteristic bone erosion and trabecular thinning. a Representative $\mu C T$ scans of caudal motion segments of 16-week-old spines showing gross trabecular thinning. b-h Bone volume/trabecular volume (BV/TV), trabecular number (Tb.n), trabecular spacing (Tb.s), trabecular thickness (Tb.th), vertebral body length, disc height, and disc height index (DHI) of Tg197 and wild-type mice (mean \pm SD) ( $n=10$ per genotype with 3 consecutive vertebrae/animal). Scatter plots show all data points and plotted as mean \pm SD. $t$ test. ns $=$ not significant, ${ }^{* *} p \leq$ $0.01,{ }^{* * * *} p \leq 0.0001$ 
breach and exposure of NP to the immune system include disrupting the skin, which alone can cause a pain response secondary to an immune response ${ }^{48}$. The immune response to herniation presented herein resembles the response present in human surgical samples; CD68positive cells are found in the NP space in both Tg197 mice and human surgical samples ${ }^{11}$. Additionally, mast cells were a significant part of the immune response after spontaneous herniation in Tg197 mice and were recently reported in painful human NP tissue ${ }^{49}$. The presence of $\mathrm{T}$ cells in the NP extrusion sample further supports the importance of $\mathrm{T}$ cell response in disc disease; Kepler et al. found high levels of regulated $\mathrm{T}$ cell expressed and secreted/C-C motif ligand 5 in painful intervertebral $\operatorname{discs}^{50}$. The pathogenesis of the herniation in Tg197 mice was not clear since there were no discernable differences in the AF extracellular matrix and the organization of the collagen fibrils between the Tg197 and WT mice. However, it is possible that elevated levels of IL-1 $\beta$ and IL-6 within the NP compartment may have reduced the integrity of the already eroded underlying vertebral bone, and this contributed to the increased incidence of failure at the endplate-AF junction at select levels.

A dogma in disc research is the notion that cytokines are a result and driver of disc degeneration. However, intact Tg197 spinal levels, which evidenced severe vertebral inflammation, had discs that were largely unaffected. The histological studies revealed that distribution of NP and AF grades in Tg197 mice were either similar or in the case of the lumbar NP significantly better than the WT animals. While there is a link between bone inflammation, Modic changes, and LBP, the lack of an overt disc phenotype in the Tg197 mice with severe vertebral inflammation disputes the hypothesis that bone inflammation is a driver of disc degeneration. Moreover, considering both the body of research linking elevated cytokine levels to disc degeneration and the severe arthritic phenotype of these animals, the finding that discs in TNF- $\alpha$ transgenic mice maintained their health was surprising. Furthermore, the lower average grades of the lumbar discs in Tg197 mice suggested that the mutant discs were not just functional but in a healthier state than the controls. It is interesting to note that $\mathrm{SM} / \mathrm{J}$ mice, a recently reported model of early onset spontaneous disc degeneration, are characterized by reduced systemic TNF$\alpha$ levels when compared with C57BL/6 mice, suggesting a disconnect between TNF- $\alpha$ levels and extent of disc degeneration $^{7,51}$. The healthier NP grades in Tg197 reflected the increased NP cellularity, which is an important criterion in the modified Thompson grading scheme. However, since the NP compartment is avascular and depends primarily on diffusion for both gaseous and nutrition exchange, the long-term implications of increased cellularity in relationship to disc aging are not entirely clear ${ }^{52}$. It is plausible that, with increasing age and sclerosis of endplates, the NP compartment may not be able to support the increased metabolic demands of its cells, and this fact alone may promote degeneration ${ }^{53-55}$. Another surprising finding was that, despite the increased cellularity of the $\operatorname{Tg} 197$ mice, the aspect ratio of the NP compartment was similar between the two genotypes. This further confirms the normal phenotype of intact Tg197 discs since changes in disc shape and size are associated with human disc degeneration ${ }^{56}$.

While the most striking effect of constitutive expression of hTNF- $\alpha$ on the intact discs was increased cell number and size, our results indicate that the difference did not arise from increased cell death in WT animals. Instead, the change was likely due to increased NP cell proliferation during early postnatal life in Tg197 mice, as proliferation of NP cells takes place within the first 3 weeks after birth ${ }^{57}$. For this reason, the lack of CDK4 staining in Tg197 and WT mice was not surprising. These findings indicate that the aberrant proliferation of NP cells at these later post-natal time points was not the cause of the observed increase in cell number. Consequently, a conditional approach using disc-specific Cre drivers (e.g., foxA2-Cre or shh-CreERT2) to drive TNF- $\alpha$ overexpression in the NP could discern the age at which TNF$\alpha$ leads to NP cell proliferation and whether the observed effects are due to local production or diffusion of systemic TNF- $\alpha$ into the disc. Nonetheless, it is important to note that, while late-stage degeneration is associated with reduced cellularity, clusters of proliferating cells exist in the early stages of degeneration ${ }^{58}$. From this viewpoint, the results clearly showed that systemic overexpression of TNF- $\alpha$ affects the disc, whether this effect was transduced through an indirect action of TNF- $\alpha$ or directly through the pro-survival and pro-proliferative actions of TNFRII remains to be $\operatorname{seen}^{59,60}$. From a clinical perspective, it is interesting to note that, following discectomy to correct lumbar disc herniation, higher levels of TNFRII protein were correlated with positive pain outcomes; in contrast, raised levels of TNFRI is associated with negative outcomes, suggesting opposing activities of these two TNF- $\alpha$ receptors in human disc disease ${ }^{61}$. Another possibility is that the $\operatorname{Tg} 197$ mice were able to block the deleterious effects of hTNF- $\alpha$ by producing endogenous TNF- $\alpha$ inhibitors such as sTNFR or progranulin $^{62,63}$. Recent studies have shown early-onset disc degeneration in progranulin and IL-1ra knockout mice implying the importance of endogenous TNF- $\alpha$ and IL- $1 \beta$ inhibitors in the maintenance of disc health $^{64,65}$. The idea that increased progranulin production protects the Tg197 mice from disc degeneration is also supported by evidence showing that progranulin promotes proliferation of numerous cell types $^{66-68}$. 
In summary, while elevated systemic TNF- $\alpha$ is insufficient to promote disc degeneration in intact discs, it predisposes mice to spontaneous herniation. Clinically, herniation and disc degeneration are closely linked: the presence of AF tears leads to significantly worse disc scores ${ }^{69}$. From this perspective, the Tg197 mutant provides a new and exciting animal model to explore many of the closely held assumptions concerning NP cell function and the relationships among systemic inflammation, vertebral inflammation, disc health, and degenerative disc disease.

\section{Materials and methods}

Mice

All animal care procedures, housing, breading, and the collection of animal tissues, were performed in accordance with a protocol approved by the Institutional Animal Care and Use Committee of Thomas Jefferson University. The Tg197 transgenic mice between the ages of 12 and 16 weeks harbor five copies of hTNF- $\alpha$ transgene previously described by Kollias and colleagues ${ }^{34}$. Both male and female mice were used in these studies.

\section{Micro-CT analysis}

Micro-CT scans (MicroCT40, SCANCO Medical, Switzerland) were performed on the lumbar and caudal levels of Tg197 and WT mice fixed with $4 \%$ paraformaldehyde. Ten mice per genotype were used and data was averaged as a mean of 2-3 spinal levels, all levels were plotted. Segments were scanned with an energy of $70 \mathrm{kVp}$, a current of $114 \mathrm{~mA}$, and a 200 -ms integration time producing a resolution of $16 \mathrm{~mm}^{3}$ voxel size. Trabecular bone three-dimensional reconstructions of these scans were compiled using Gaussian filter $(\sigma=1.0$, support $=1)$ and converted to binary images with a fixed gray-scale threshold of 200. The data sets were then assessed using the software supplied by the system manufacturer. DHI was calculated by dividing average disc height by height of adjacent vertebral bodies.

\section{Histological analysis}

Spines were decalcified in $20 \%$ ethylenediaminetetracetic acid (EDTA) at $4{ }^{\circ} \mathrm{C}$ for 15 days before embedding in paraffin and $7-\mu \mathrm{m}$ mid-coronal sections were prepared. Xylene deparaffinization followed by graded ethanol rehydration preceded all staining protocols. Safranin O/ Fast Green/Hematoxylin-stained slides were imaged using Axio Imager 2 microscope, $5 \times / 0.15 \mathrm{~N}$-Achroplan or $10 \times /$ 0.3 EC Plan-Neofluar objectives, Axiocam 105 color camera, and Zen2TM software (Carl Zeiss). Scoring was performed using a modified Thompson grading scale (S1) by $5-7$ blinded observers ${ }^{70,71}$. Endplate scoring was performed by five blinded observers following Boos criterion $^{37}$. Ten mice per genotype with three discs per mouse in both caudal and lumbar levels were used.

\section{Picrosirius Red ${ }^{\mathrm{TM}}$ analysis}

Picrosirius $\operatorname{Red}^{\mathrm{TM}}$ staining visualized localization and quality of the collagen fibrils ${ }^{40,72}$. Stained sections were imaged on a polarizing microscope (Eclipse LV100 POL, Nikon $)^{7}$. Images containing only the AF were used for the subsequent analysis of the surface area occupied by green, yellow, or red pixels. Threshold levels for these three colors remained constant for analysis of all samples.

\section{Cell number quantification}

DAPI (4,6-diamidino-2-phenylindole; Thermo Fisher Scientific, P36934) stained mid-coronal $7-\mu \mathrm{m}$ sections were used to quantify the cell number in the NP. Three sections per animal $(n=10)$ were used, and the NP area was used for analysis. Using the ImageJ software (NIH), images were converted to 32-bit, then the background was subtracted using rolling $=50$, next the images were autothresholded, made binary, and then cell number was calculated using the analyze particles function ${ }^{73}$.

\section{Immunofluorescence microscopy}

Mid-coronal 7- $\mu \mathrm{m}$ sections were used for all immunofluorescence studies. Quantitative staining for IL-6, IL-1 $\beta$, ARGxx, and DIPEN was performed on six animals per genotype, while for NP phenotypic makers and some matrix molecules (CS and Acan) three animals per genotype were used. Sections were de-paraffinized and rehydrated as described above before antigen retrieval. Antigen retrieval was accomplished in an antibodyspecific manner by either heated citrate buffer for $20 \mathrm{~min}$ or proteinase $\mathrm{K}$ for $10 \mathrm{~min}$ at room temperature or Chondroitinase $\mathrm{ABC}$ for $30 \mathrm{~min}$ at $37^{\circ} \mathrm{C}$ or TRIS/EDTA. Sections were blocked in $5 \%$ normal serum (Thermo Fisher Scientific, 10000 C) in PBS-T (0.4\% Triton X-100 in phosphate-buffered saline (PBS)), and incubated with the primary antibody. The primary antibodies used were Aggrecan (1:50, Millipore, AB1031), Collagen I (1:100, Abcam, ab34710), Collagen II (1:400, Fitzgerald, 70RCR008), Collagen X (1:500, Abcam, ab58632), CA3 (1:150, Santa Cruz, sc-50715), KRT19 (1:3, DSHB, TROMA-III/ supernatant), IL-1 $\beta$ (1:100, Novus, NB600-633), CD8 (1:1000, Abcam, ab209775), CD4 (1:1000, Abcam, ab183685), Ly6 (1:500, Abcam, ab2557), CD68 (1:500, Abcam, ab125212), CD31 (1:1000, Abcam 124432), or MMP13 (1:200, Abcam, ab39012) in blocking buffer at $4{ }^{\circ} \mathrm{C}$ overnight. For GLUT-1 (1:200, Abcam, ab40084), ARGxx (1:200, Abcam, ab3773), CS (1:300, Abcam, ab11570), DIPEN (1:500, mdbiosciences, 1042002), IL-6 
(1:50, Novus, NB600-1131), and tryptase (1:1000, Abcam, ab2378) staining, Mouse on Mouse Kit (Vector laboratories, BMK-2202) was used for blocking and primary antibody incubation. Tissue sections were washed and incubated with the appropriate Alexa Fluor ${ }^{\circledR}-594$ conjugated secondary antibody (Jackson ImmunoResearch), at a dilution of 1:700 for $1 \mathrm{~h}$ at room temperature in dark. The sections were washed again with PBS-T $(0.4 \%$ Triton X-100 in PBS) and mounted with ProLong ${ }^{\circledR}$ Gold Antifade Mountant with DAPI (Thermo Fisher Scientific, P36934). All mounted slides were allowed to set overnight before visualization with Axio Imager 2 using $5 \times / 0.15 \mathrm{~N}$ Achroplan or $10 \times / 0.3$ EC Plan-Neofluar objectives, AxioCam MRm camera, and Zen2TM software (Carl Zeiss). Exposure settings remained constant for all genotypes. Staining percentage of area quantification was performed using the ImageJ software (NIH), thresholds remained constant for each antibody.

\section{TUNEL assay}

TUNEL assay was performed on disc tissue sections using an "In situ cell death detection" Kit (Roche Diagnostic) ${ }^{7}$. Sections were permeabilized with Proteinase $\mathrm{K}$ $(20 \mu \mathrm{g} / \mathrm{mL})$ for $15 \mathrm{~min}$ at room temperature before the TUNEL assay and imaged as described above.

\section{Protein extraction and western blotting}

Following sacrifice, NP material from lumbar and caudal discs was surgically isolated and homogenized in $\mathrm{T}^{-\mathrm{PER}^{\mathrm{TM}}}{ }^{\mathrm{T}}, 1 \times$ protease inhibitor mixture (Roche), NaF $(5 \mathrm{nM})$, and $\mathrm{Na}_{3} \mathrm{VO}_{4}(200 \mu \mathrm{m})$. Proteins were resolved on a $10 \%$ sodium dodecyl sulfate-polyacrylamide gel and transferred by electroblotting to polyvinylidene difluoride membranes (Bio-Rad). Ponceau S staining $(0.1 \%(\mathrm{w} / \mathrm{v})$ Ponceau in $5 \%(\mathrm{v} / \mathrm{v})$ acetic acid) verified equal protein loading. The membranes were washed with TBS and blocked with 5\% nonfat dray milk in TBS with Tween 20 and incubated overnight with $\alpha$ hTNF antibody (1:1000, ab6671, rabbit, Abcam) and then with appropriate secondary antibodies for $1 \mathrm{~h}$ at room temperature. Immunolabeling was detected using the ECL reagent (Amersham Biosciences). Recombinant hTNF and mTNF (PeproTech) was used to verify antibody specificity.

\section{Statistics}

Ten animals per genotype per time point were used for analysis $(n=10)$, and data are presented as mean \pm SD. Differences between genotypes were analyzed using the Student's $t$ test when only two groups presented on graph or one-way analyses of variance with Sidak's multiple comparison test between groups. Three lumber or tail levels per mouse were combined and averaged for both $\mu \mathrm{CT}$ and histological analysis. At least five independent blinded individuals performed histological grading.
Significance between collagen fiber distributions was determined using $X^{2}$ test. All statistical analyses were done using Prism7 (GraphPad Software). $p \leq 0.05$ was the threshold for statistical significance.

\section{Acknowledgements}

This study was funded by National Institute of Arthritis and Musculoskeletal and Skin Diseases (NIAMS) of the National Institutes of Health under Award Numbers AR055655, AR064733, T32 AR052273, and F30AR071256.

\section{Authors' contributions}

Study design, data interpretation, revising manuscript content, and approving the final version of manuscript: all the authors. Study conduct, data collection, data analysis, drafting the manuscript, responsibility for the integrity of the data analysis: D.J.G.

\section{Conflict of interest}

The authors declare that they have no conflict of interest.

\section{Publisher's note}

Springer Nature remains neutral with regard to jurisdictional claims in published maps and institutional affiliations.

Supplementary Information accompanies this paper at (https://doi.org/ 10.1038/s41419-018-1246-x).

Received: 15 August 2018 Revised: 2 November 2018 Accepted: 21 November 2018

Published online: 18 December 2018

\section{References}

1. Katz, J. N. Lumbar disc disorders and low-back pain: socioeconomic factors and consequences. J. Bone Jt. Surg. Am. 88(Suppl 2), 21-24 (2006).

2. Murray, C. J. L. et al. The state of US health, 1990-2010: burden of diseases, injuries, and risk factors. JAMA 310, 591-608 (2013).

3. Vos, T. et al. Global, regional, and national incidence, prevalence, and years lived with disability for 301 acute and chronic diseases and injuries in 188 countries, 1990-2013: a systematic analysis for the Global Burden of Disease Study 2013. Lancet 386, 743-800 (2015).

4. Arnbak, B. et al. Prevalence of degenerative and spondyloarthritis-related magnetic resonance imaging findings in the spine and sacroiliac joints in patients with persistent low back pain. Eur. Radiol. 26, 1191-1203 (2015).

5. Livshits, G. et al. Lumbar disc degeneration and genetic factors are the main risk factors for low back pain in women: the UK Twin Spine Study. Ann. Rheum. Dis. 70, 1740-1745 (2011).

6. Silagi, E. S., Shapiro, I. M. \& Risbud, M. V. Glycosaminoglycan synthesis in the nucleus pulposus: Dysregulation and the pathogenesis of disc degeneration. Matrix Biol. https://doi.org/10.1016/j.matbio.2018.02.025 (2018).

7. Choi, H. et al. A novel mouse model of intervertebral disc degeneration shows altered cell fate and matrix homeostasis. Matrix Biol. 70, 102-122 (2018).

8. Zhang, Y. et al. Early onset of disc degeneration in SM/J mice is associated with changes in ion transport systems and fibrotic events. Matrix Biol. 70 123-139 (2018).

9. Pan, H. et al. RNA binding protein HuR regulates extracellular matrix gene expression and $\mathrm{pH}$ homeostasis independent of controlling HIF-1a signaling in nucleus pulposus cells. Matrix Biol. https://doi.org/10.1016/j. matbio.2018.08.003 (2018).

10. Le Maitre, C. L., Hoyland, J. A. \& Freemont, A. J. Catabolic cytokine expression in degenerate and herniated human intervertebral discs: LL-1 beta and TNFalpha expression profile. Arthritis Res. Ther. 9, R77 (2007).

11. Shamji, M. F. et al. Proinflammatory cytokine expression profile in degenerated and herniated human intervertebral disc tissues. Arthritis Rheum. 62, 1974-1982 (2010).

12. Risbud, M. V. \& Shapiro, I. M. Role of cytokines in intervertebral disc degeneration: pain and disc content. Nat. Rev. Rheumatol. 10, 44-56 (2014). 
13. Johnson, Z. I. et al. TNF-a promotes nuclear enrichment of the transcription factor TonEBP/NFAT5 to selectively control inflammatory but not osmoregulatory responses in nucleus pulposus cells. J. Biol. Chem. 292, 17561-17575 (2017).

14. Wang, $X$. et al. Tumor necrosis factor-a- and interleukin-1 $\beta$-dependent matrix metalloproteinase-3 expression in nucleus pulposus cells requires cooperative signaling via syndecan 4 and mitogen-activated protein kinase-nuclear factor KB axis: implications in inflammatory disc disease. Am. J. Pathol. 184, 1-13 (2014).

15. Wang, J. et al. Tumor necrosis factor $a$ - and interleukin-1ß-dependent induction of CCL3 expression by nucleus pulposus cells promotes macrophage migration through CCR1. Arthritis Rheum. 65, 832-842 (2013).

16. Murata, Y. et al. Local application of interleukin- 6 to the dorsal root ganglion induces tumor necrosis factor-a in the dorsal root ganglion and results in apoptosis of the dorsal root ganglion cells. Spine (Phila. Pa 1976). 36, 926-932 (2011).

17. Murata, Y., Nannmark, U., Rydevik, B., Takahashi, K. \& Olmarker, K. The role of tumor necrosis factor-a in apoptosis of dorsal root ganglion cells induced by herniated nucleus pulposus in rats. Spine (Phila. Pa 1976). 33, 155-162 (2008).

18. MacEwan, D. J. TNF receptor subtype signalling: differences and cellular consequences. Cell. Signal. 14, 477-492 (2002)

19. MacEwan, D. J. TNF ligands and receptors - a matter of life and death. Br. J. Pharmacol. 135, 855-875 (2002).

20. Johnson, Z. I., Schoepflin, Z. R., Choi, H., Shapiro, I. M. \& Risbud, M. V. Disc in flames: roles of TNF- $\alpha$ and $\mathrm{IL}-1 \beta$ in intervertebral disc degeneration. Eur. Cell. Mater. 30, 104-116 (2015). discussion 116-7.

21. Wang, Z., Hutton, W. C. \& Yoon, S. T. Bone morphogenetic protein-7 antagonizes tumor necrosis factor- $a$-induced activation of nuclear factor $\mathrm{KB}$ and up-regulation of the ADAMTS, leading to decreased degradation of disc matrix macromolecules aggrecan and collagen II. Spine J. 14, 505-512 (2014).

22. Kim, H.J. et al. Anti-inflammatory effect of platelet-rich plasma on nucleus pulposus cells with response of TNF-a and IL-1. J. Orthop. Res. 32, 551-556 (2014).

23. Liu, $\mathrm{H}$. et al. LIM mineralization protein-1 suppresses TNF-a induced intervertebral disc degeneration by maintaining nucleus pulposus extracellular matrix production and inhibiting matrix metalloproteinases expression. J. Orthop. Res. 33, 294-303 (2015).

24. Weber, K. T. et al. Serum levels of the proinflammatory cytokine interleukin- 6 vary based on diagnoses in individuals with lumbar intervertebral disc diseases. Arthritis Res. Ther. 18, 3 (2016).

25. Zu, B., Pan, H., Zhang, X.-J. \& Yin, Z.-S. Serum levels of the inflammatory cytokines in patients with lumbar radicular pain due to disc herniation. Asian Spine J. 10, 843-849 (2016).

26. Nilsson, E., Nakamae, T. \& Olmarker, K. Pain behavior changes following disc puncture relate to nucleus pulposus rather than to the disc injury per se: an experimental study in rats. Open Orthop. J. 5, 72-77 (2011).

27. Lai, A. et al. Annular puncture with tumor necrosis factor-alpha injection enhances painful behavior with disc degeneration in vivo. Spine J. 16, 420-431 (2016).

28. Hotamisligil, G. S., Arner, P., Caro, J. F., Atkinson, R. L. \& Spiegelman, B. M. Rapid publication increased adipose tissue expression of tumor necrosis factor-a in human obesity and insulin resistance. J. Clin. Invest. 95, 2409-2415 (1995).

29. Lee, J.-H. et al. Cytokine profile of peripheral blood in type 2 diabetes mellitus patients with diabetic retinopathy. Ann. Clin. Lab. Sci. 38, 361-367 (2008).

30. Goyal, R., Faizy, A. F., Siddiqui, S. S. \& Singhai, M. Evaluation of TNF-a and IL-6 levels in obese and non-obese diabetics: pre- and postinsulin effects. N. Am. J. Med. Sci. 4, 180-184 (2012)

31. Jensen, T. S., Karppinen, J., Sorensen, J. S., Niinimäki, J. \& Leboeuf-Yde, C. Vertebral endplate signal changes (Modic change): a systematic literature review of prevalence and association with non-specific low back pain. Eur. Spine J. 17, 1407-1422 (2008).

32. Modic, M. T., Steinberg, P. M., Ross, J. S., Masaryk, T. J. \& Carter, J. R. Degenerative disk disease: assessment of changes in vertebral body marrow with MR imaging. Radiology 166, 193-199 (1988).

33. Papuga, M. O. et al. TNF is required for the induction but not the maintenance of compression-induced BME signals in murine tail vertebrae: limitations of anti-TNF therapy for degenerative disc disease. J. Orthop. Res. 29, 1367-1374 (2011).

34. Keffer, J. et al. Transgenic mice expressing human tumour necrosis factor: a predictive genetic model of arthritis. EMBO J. 10, 4025-4031 (1991).
35. Hayer, S. et al. Tenosynovitis and osteoclast formation as the initial preclinical changes in a murine model of inflammatory arthritis. Arthritis Rheum. 56, 79-88 (2007).

36. Zwerina, J. et al. TNF-induced structural joint damage is mediated by IL-1. Proc. Natl Acad. Sci. USA 104, 11742-11747 (2007).

37. Boos, N. et al. Classification of age-related changes in lumbar intervertebral discs: 2002 Volvo Award in basic science. Spine (Phila. Pa 1976). 27, 2631-2644 (2002).

38. Wang, J. et al. TNF- $\alpha$ and IL-1 $\beta$ promote a disintegrin-like and metalloprotease with thrombospondin type | motif-5-mediated aggrecan degradation through syndecan-4 in intervertebral disc. J. Biol. Chem. 286, 39738-39749 (2011).

39. Binch, A. L. A., Shapiro, I. M. \& Risbud, M. V. Syndecan-4 in intervertebral disc and cartilage: saint or synner? Matrix Biol. 52-54, 355-362 (2016).

40. Steplewski, A. et al. Blocking collagen fibril formation in injured knees reduces flexion contracture in a rabbit model. J. Orthop. Res. 35, 1038-1046 (2017).

41. Bedore, J. et al. Loss of notochord-derived CCN2 results in impaired intervertebral disc development and premature disc degeneration. Arthritis Rheum. 65, n/a-n/a (2013).

42. Risbud, M. V. et al. Defining the phenotype of young healthy nucleus pulposus cells: recommendations of the Spine Research Interest Group at the 2014 annual ORS meeting. J. Orthop. Res. 33, 283-293 (2015).

43. Silagi, E. S., Batista, P., Shapiro, I. M. \& Risbud, M. V. Expression of carbonic anhydrase III, a nucleus pulposus phenotypic marker, is hypoxia-responsive and confers protection from oxidative stress-induced cell death. Sci. Rep. 8 4856 (2018).

44. Rajasekaran, S., Bajaj, N., Tubaki, V., Kanna, R. M. \& Shetty, A. P. ISSLS Prize Winner. Spine (Phila. Pa 1976). 38, 1491-1500 (2013).

45. Daly, C., Ghosh, P., Jenkin, G., Oehme, D. \& Goldschlager, T. A review of animal models of intervertebral disc degeneration: pathophysiology, regeneration, and translation to the clinic. Biomed. Res. Int. 2016, 5952165 (2016).

46. Gruber, H. E. et al. Targeted deletion of the SPARC gene accelerates disc degeneration in the aging mouse. J. Histochem. Cytochem. 53, 1131-1138 (2005).

47. Chiu, C.-C. et al. The probability of spontaneous regression of lumbar herniated disc: a systematic review. Clin. Rehabil. 29, 184-195 (2015).

48. Lai, A. et al. Assessment of functional and behavioral changes sensitive to painful disc degeneration. J. Orthop. Res. 33, 755-764 (2015).

49. Wiet, M. G. et al. Mast cell-intervertebral disc cell interactions regulate inflammation, catabolism and angiogenesis in discogenic back pain. Sci. Rep. 7, 12492 (2017)

50. Kepler, C. K. et al. Expression and relationship of proinflammatory chemokine RANTES/CCL5 and cytokine IL-1 $\beta$ in painful human intervertebral discs. Spine (Phila. Pa 1976). 38, 873-880 (2013).

51. Jacob, C. O., Lee, S. K. \& Strassmann, G. Mutational analysis of TNF-alpha gene reveals a regulatory role for the 3 '-untranslated region in the genetic predisposition to lupus-like autoimmune disease. J. Immunol. 156, 3043-3050 (1996).

52. Risbud, M. V., Schipani, E. \& Shapiro, I. M. Hypoxic regulation of nucleus pulposus cell survival. Am. J. Pathol. 176, 1577-1583 (2010).

53. Silagi, E. S. et al. Bicarbonate recycling by HIF-1-dependent carbonic anhydrase isoforms 9 and 12 is critical in maintaining intracellular $\mathrm{pH}$ and viability of nucleus pulposus cells. J. Bone Miner. Res. 33, 338-355 (2018).

54. Choi, $\mathrm{H}$. et al. Hypoxia promotes noncanonical autophagy in nucleus pulposus cells independent of MTOR and HIF1A signaling. Autophagy 12, 1631-1646 (2016).

55. Agrawal, A. et al. Normoxic stabilization of HIF-1a drives glycolytic metabolism and regulates aggrecan gene expression in nucleus pulposus cells of the rat intervertebral disk. Am. J. Physiol. Physiol. 293, C621-C631 (2007).

56. Pfirrmann, C. W. A., Metzdorf, A., Elfering, A., Hodler, J. \& Boos, N. Effect of aging and degeneration on disc volume and shape: a quantitative study in asymptomatic volunteers. J. Orthop. Res. 24, 1086-1094 (2006).

57. Dahia, C. L., Mahoney, E. J., Durrani, A. A. \& Wylie, C. Postnatal growth, differentiation, and aging of the mouse intervertebral disc. Spine (Phila. Pa 1976). 34, 447-455 (2009).

58. Johnson, W. E. B., Eisenstein, S. M. \& Roberts, S. Cell cluster formation in degenerate lumbar intervertebral discs is associated with increased disc cell proliferation. Connect. Tissue Res. 42, 197-207 (2001).

59. Sakkou, M. et al. Mesenchymal TNFR2 promotes the development of polyarthritis and comorbid heart valve stenosis. JCI Insight https://doi.org/10.1172/ jci.insight.98864 (2018). 
60. Blüml, S. et al. Antiinflammatory effects of tumor necrosis factor on hematopoietic cells in a murine model of erosive arthritis. Arthritis Rheum. 62 , 1608-1619 (2010).

61. Andrade, P. et al. Tumor necrosis factor-a levels correlate with postoperative pain severity in lumbar disc hernia patients: opposite clinical effects between tumor necrosis factor receptor 1 and 2. Pain 152, 2645-2652 (2011)

62. Tang, W. et al. The growth factor progranulin binds to TNF receptors and is therapeutic against inflammatory arthritis in mice. Science 332, 478-484 (2011).

63. Uddin, S. M. et al. Progranulin inhibition of TNFa. Immunol. Cell Biol. 92, 299-300 (2014).

64. Zhao, Y. et al. Progranulin knockout accelerates intervertebral disc degeneration in aging mice. Sci. Rep. 5, 9102 (2015).

65. Phillips, K. L. E., Jordan-Mahy, N., Nicklin, M. J. H. \& Le Maitre, C. L. Interleukin-1 receptor antagonist deficient mice provide insights into pathogenesis of human intervertebral disc degeneration. Ann. Rheum. Dis. 72, 1860-1867 (2013).

66. Nedachi, T., Kawai, T., Matsuwaki, T., Yamanouchi, K. \& Nishihara, M. Progranulin enhances neural progenitor cell proliferation through glycogen synthase kinase $3 \beta$ phosphorylation. Neuroscience 185, 106-115 (2011).
67. Kuse, Y. et al. Progranulin promotes the retinal precursor cell proliferation and the photoreceptor differentiation in the mouse retina. Sci. Rep. 6, 23811 (2016).

68. He, Z. \& Bateman, A. Progranulin gene expression regulates epithelial cell growth and promotes tumor growth in vivo. Cancer Res. 59, 3222-3229 (1999).

69. Sharma, A., Pilgram, T. \& Wippold, F. J. Association between annular tears and disk degeneration: a longitudinal study. Am. J. Neuroradiol. 30, 500-506 (2009).

70. Thompson, J. P. et al. Preliminary evaluation of a scheme for grading the gross morphology of the human intervertebral disc. Spine (Phila. Pa 1976). 15, 411-415 (1990).

71. McCann, M. R. et al. Repeated exposure to high-frequency low-amplitude vibration induces degeneration of murine intervertebral discs and knee joints. Arthritis Rheumatol. 67, 2164-2175 (2015).

72. Whittaker, P., Kloner, R. A., Boughner, D. R. \& Pickering, J. G. Quantitative assessment of myocardial collagen with picrosirius red staining and circularly polarized light. Basic Res. Cardiol. 89, 397-410 (1994).

73. Schneider, C. A., Rasband, W. S. \& Eliceiri, K. W. NIH Image to ImageJ: 25 years of image analysis. Nat. Methods 9, 671-675 (2012). 